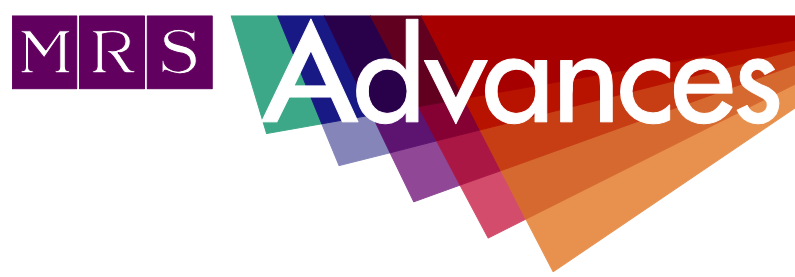

\title{
High discharge capacities of Ti-based quasicrystal electrodes synthesized by mechanical alloying - RETRACTION
}

DEDETEMO KIMILITA PATRICK, AKITO TAKASAKI and ALICJA KLIMKOWICZ

The authors of this article [1] retract this paper. After publication, an error was discovered in the chemical composition used to calculate the mass in the container during mechanical alloying, which results in a significant change in discharge capacity in the published paper's results.

Reference

1. PATRICK, D., TAKASAKI, A., \& KLIMKOWICZ, A. (2018). High discharge capacities of Ti-based quasicrystal electrodes synthesized by mechanical alloying. MRS Advances, 3(38), 2271-2279. doi:10.1557/adv.2018.346 